\title{
A Pericardiophrenic Collateral Pathway in Portal Hypertension
}

\author{
Dong Hun Kim, M.D., Hancheol Jo, M.D., Jeongseok Yun, M.D., Ph.D. \\ Department of Surgery, Trauma Center, Dankook University Hospital, Cheonan, Korea
}

A 70-year-old man sustained blunt trauma from rollover of a cultivator. Chest radiography showed irregular contour in the left lateral border of the heart (Fig. 1). Chest computed tomography (CT) revealed a markedly dilated pericardiophrenic vein passed along the lateral border of the heart, anastomosing to the left inferior phrenic vein and draining to the left brachiocephalic vein (Fig. 2). He had unknowingly liver cirrhosis, recognized by CT, with a Child-Pugh score of 8 (class B) caused by chronic Budd-Chiari syndrome (Fig. 3). This varicose vein may be usually due to the obstruction of the hepatic venous outflow [1]. Consequently, he had multiple fractures of left ribs with scanty pneumothorax and left renal rupture from trauma, followed by angiographic renal artery embolization. The engorged pericardiophrenic collateral pathway is a rare presentation from liver cirrhosis or Budd-Chiari syndrome [1-3], and direct traumatic injury to it probably could lead to the life-threatening massive

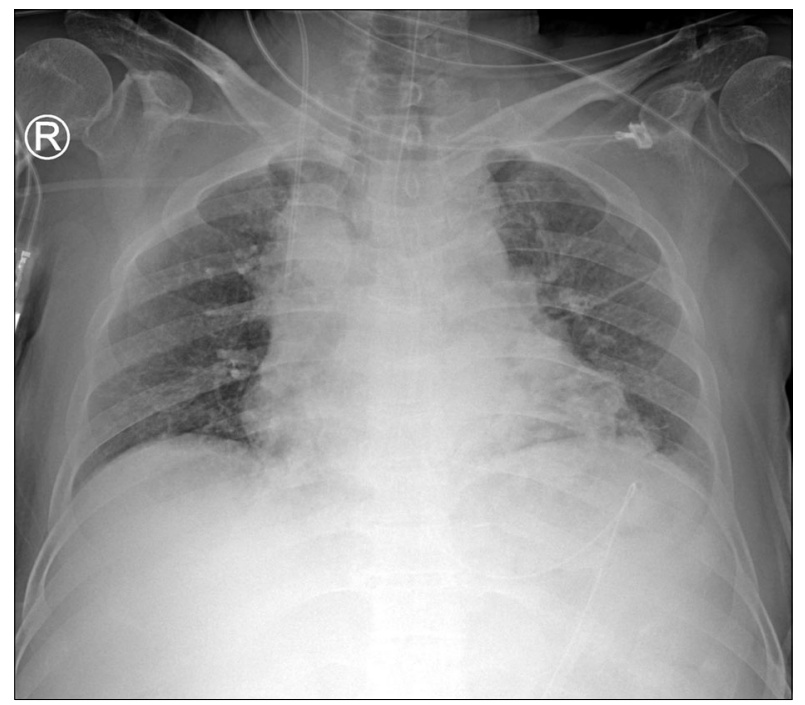

Fig. 1. Chest radiography shows irregular margin and heterogenous radiopacity at the lateral border of the left heart. hemothorax.

\section{Conflicts of Interest}

Received September 8, 2017,

Revised October 23, 2017,

Accepted November 22, 2017

Correspondence to: Dong Hun Kim, M.D.

Department of Surgery, Trauma Center,

Dankook University Hospital, 201

Manghyang-ro, Dongnam-gu, Cheonan

31116, Korea

Tel: +82-41-550-7661, Fax: +82-41-550-0039,

E-mail: saint7331@gmail.com

ORCID:

https://orcid.org/0000-0001-6613-6902

No potential conflict of interest relevant to this article was reported.

\section{References}

1. Sharma M, Rameshbabu CS. Collateral pathways in portal hypertension. J Clin Exp Hepatol 2012;2:338-52.

2. Kantarci M, Ogul H, Karaca L. A large pericardiophrenic collateral in a patient with

Copyright (C) 2019 by Korean Society of Acute Care Surgery

(c) This is an Open Access article distributed under the terms of the Creative Commons Attribution Non-Commercial License (http://creativecommons.org/licenses/by-nc/4.0) which permits unrestricted non-commercial use, distribution, and reproduction in any medium, provided the original work is properly cited.

ISSN 2288-5862(Print), ISSN 2288-9582(Online)

https://doi.org/10.17479/jacs.2019.9.1.25 

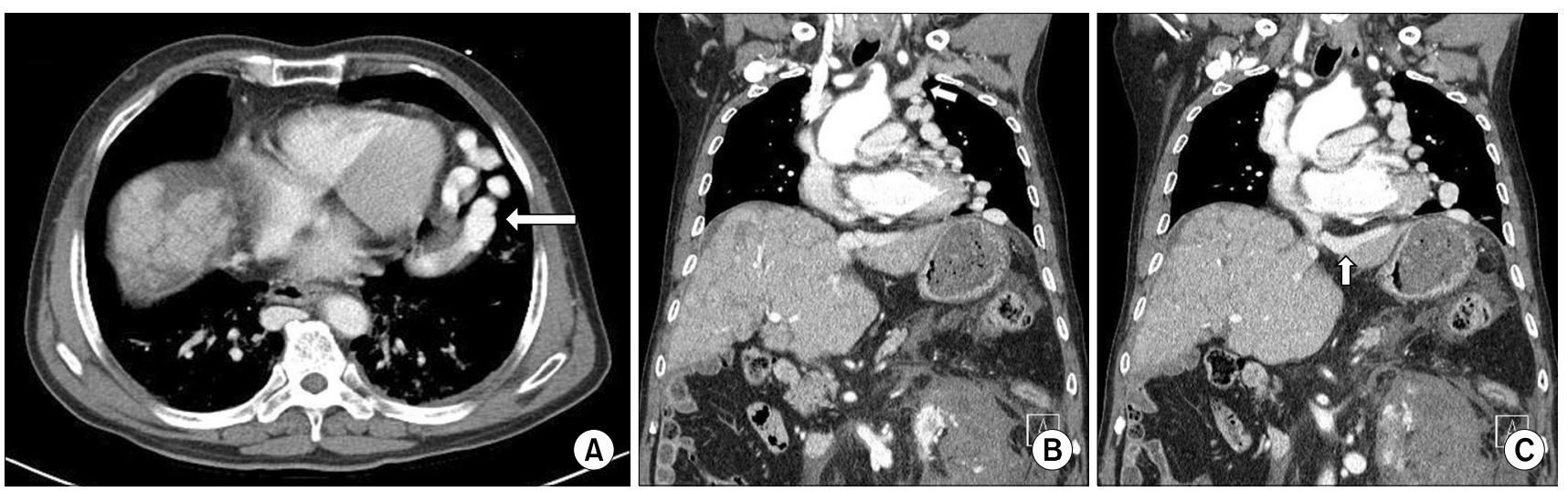

Fig. 2. Chest computed tomography shows (A) a markedly engorged vessel (arrow) adjacent to the left ventricle in the mediastinum, (B) a dilated pericardiophrenic vein along the lateral border of the heart draining to the left brachiocephalic vein (arrow), and (C) dilatation of the left inferior phrenic vein (arrow) anastomosing to the pericardiophrenic vein.

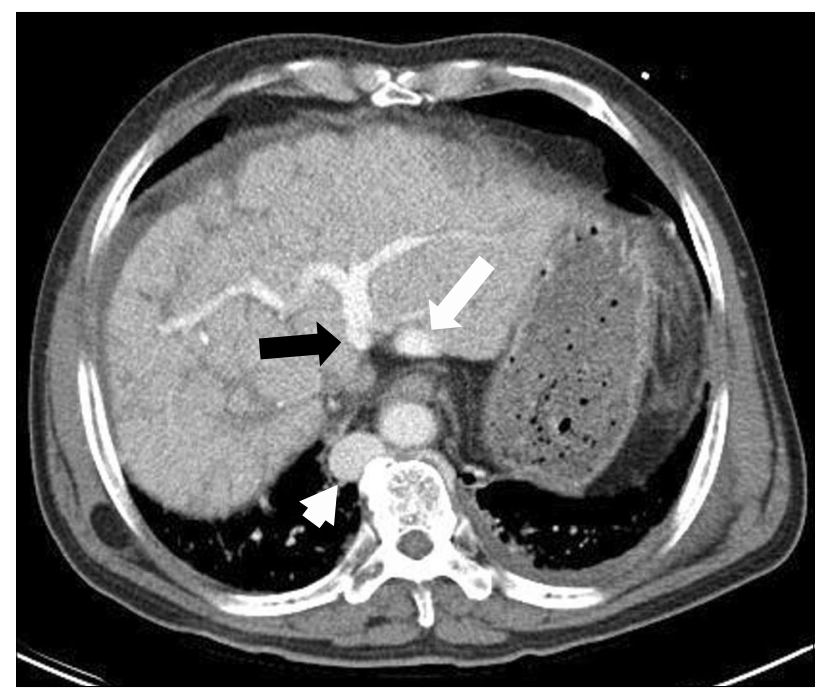

Fig. 3. Abdomen computed tomography shows liver cirrhosis with IVC obliteration, dilatation and outflow stenosis of common trunk of left and middle hepatic vein (black arrow), corresponding to imaging features of the Budd-Chiari syndrome (white arrow: left inferior phrenic vein, white arrowhead: azygos vein).
Budd-Chiari syndrome. Eur J Cardiothorac Surg 2015;47:387.

3. Widrich WC, Srinivasan M, Semine MC, Robbins AH. Collateral pathways of the left gastric vein in portal hypertension. AJR Am J Roentgenol 1984;142:375-82. 